\title{
From Helpless to Hero: Promoting Values-Based Behavior and Positive Family Interaction in the Midst of COVID-19
}

\author{
Thomas G. Szabo ${ }^{1}$ (D) Sarah Richling ${ }^{2} \cdot$ Dennis D. Embry ${ }^{3} \cdot$ Anthony Biglan $^{4} \cdot$ Kelly G. Wilson ${ }^{5}$
}

Published online: 23 April 2020

(C) Association for Behavior Analysis International 2020

\begin{abstract}
Parents managing their home environments during government-ordered stay-at-home periods are likely to need new skills for occupying their children's time with activities that promote health and emotional well-being. Moreover, parents and children know they need help managing these circumstances. Perhaps for the first time, behavior analysts hold the reinforcers for increasing parental involvement in effective child-rearing practices. In fact, behavior analysts can help parents enlist their children in managing the household by framing their behavior in terms of hidden superpowers. In the current article, we argue that behavior analysts have a range of tools to offer that are grounded in evidence-based principles, strategies, and kernels—or essential units of behavioral influence. When combined into scheduled daily practices and invoked by children taught to see their use of the tools as nothing short of heroic, these practices function as "vaccinations" that inoculate families against toxic and unsafe behaviors.
\end{abstract}

Keywords Acceptance and commitment training $\cdot$ COVID-19 $\cdot$ Kernels $\cdot$ Parenting $\cdot$ PAX Good Behavior Game $\cdot$ Values

Children's books and Pixar movies are filled with feel-good stories about kids who save the world or take out bad guys threatening their homes. However, when you ask most children what their superpowers are, you may be met with a

\footnotetext{
Editor's Note

This manuscript is being published on a highly expedited basis, as part of a series of emergency publications designed to help practitioners of applied behavior analysis take immediate action to adjust to and mitigate the COVID-19 crisis. This article was submitted on April 1, 2020, and received final acceptance on April 2, 2020. The journal would like to especially thank Courtney Tarbox for her expeditious review of the manuscript. The views and strategies suggested by the articles in this series do not represent the positions of the Association for Behavior Analysis International or Springer Nature.
}

Thomas G. Szabo

tszabo@fit.edu

1 Florida Institute of Technology, 150 W. University Blvd., Melbourne, FL 32901, USA

2 Auburn University, Auburn, AL, USA

3 PAXIS Institute, Tucson, AZ, USA

4 Oregon Research Institute, Eugene, OR, USA

5 One Life Education and Training, Tucson, AZ, USA quizzical blank stare. "I'm not a hero," most children will say with an embarrassed grimace. Our stance, and one we hope you will adopt, is that this is far from the truth. In this article, we present simple practices that behavior analysts and related personnel can teach to make everyone in the family a hero. The practices we present are grounded in evidencebased principles, strategies, and kernels that can be combined in clusters that serve to "vaccinate" against toxic and unsafe behavior. Some of the behavioral vaccines, kernels, or practices have been used to mitigate serious social crises: the Gulf War (Embry, 1991), the Twin Towers attacks and 9/11 (Embry, 2006), and school shootings in the 1990s (Embry, Flannery, Vazsonyi, Powell, \& Atha, 1996; Krug, Brener, Dahlberg, Ryan, \& Powell, 1997). Others have been applied to problems related to parenting (e.g., Murrell, Wilson, LaBorde, Drake, \& Rogers, 2008), parenting children with autism (e.g., Corti et al., 2018), treating rule inflexibility in children with autism (Szabo, 2019), and behavioral treatment in the context of adolescent posttraumatic stress (e.g., Woidneck, Morrison, \& Twohig, 2014). If ever we needed heroes who could administer these vaccines and, once vaccinated, go forth and inoculate others, it is now.

Perhaps no one is actually born possessing superpowers, but with a nudge from behavior science, anyone can respond to life's unknowns with powerful response persistence, 
empathy, goodwill, and patience. It will take small, daily acts of heroism to set in motion the conditions under which families will find peace during periods of stay-at-home orders. Given the vast unknowns confronting us, these small acts, performed each day, could mean the difference between a family merely surviving and thriving.

Among those unknowns surrounding the current COVID19 pandemic is the length of time families will be asked or required to stay home. For many, staying home is an unprecedented demand. Day care, school, sports, clubs, playdates, and parties that ordinarily occupy time before dinner and bedtime are off limits. Many outlets are racing to post activities for parents to try with their children. Although these strategies could be effective for some children, they may inadvertently produce unwanted outcomes for others. For example, Amlen (2020) suggested quarantined parents ask their kids to play 20 Questions, a guessing game in which the aim is to identify a person, place, or thing by asking fewer than 20 questions. The game requires several component verbal repertoires, including intraverbal conditional discrimination and relational responding with respect to arbitrary conventional cues for size, hierarchy, distinction, and coordination. Social skills required include waiting to speak and tolerating ambiguity or periodic losses. Although this game may be fun for some typically developing children who already demonstrate these skills, others receiving behavior-analytic services may engage in aggression or escape behaviors during this game due to the complexity of the verbal skills involved or the advanced social requirements for delayed gratification and friendly competition.

An additional concern involves the suggestion of games and activities without instructions for increasing prosocial, flexible, and compassionate responding in learners who lack these skills. For example, Osmanski (2020) lists several games such as setting up a treasure hunt, training the dog, and playing charades. Any one of these could be useful for children with a wide range of skills, but without guidelines for how to teach the rules, establish norms of behavior, adapt the rules for different family members, or remind and reinforce desired behavior, the suggestions could potentially lead to frustration or behavioral escalation.

The important role that behavior analysts play in supporting families during periods of social distancing and lockdown cannot be overstated. The Sierra Leonean Ebola epidemic of 2014 2016 followed just 12 years after the nation ended a brutal civil war. Reports of child abuse during Ebola soared compared to rates during the war, and importantly, the number of reported adverse childhood events that occurred in homes since then has not decreased (U.S. Department of State, 2011, 2012, 2013, 2014, 2015, 2016, 2017, 2018, 2019). A behavioral interpretation of these figures would be that once parents learned the fastest way to decrease a child's unwanted behavior was to use corporal punishment, they resorted to this class of behavior even after the lockdown ended because the negative reinforcement it produced was immediate and certain. Because punishment does not directly teach an alternative response, it is possible that children's actions that led to these parent behaviors continued, thus potentially contributing to a loop of policedocumented child abuse that persists to this day.

Fortunately, behavior analysts serving families during the COVID-19 pandemic have access to a set of evidence-based best practices that are founded in the principles of behavior and are adaptable to varying skill sets within a family. Moreover, these practices are helpful for promoting cooperation, emotional resilience, empathy, and compassionate action. The best practices we refer to herein are composed of evidence-based kernels, or irreducible units of behaviorchange technology that can be assembled into exercises that are easily adapted for children and adults with varying repertoires (Embry, 2004; Embry \& Biglan, 2008). They can be put together into routine daily clusters that can be likened to behavioral vaccinations that cost nothing, are quickly taught and learned, and inoculate against unsafe or toxic behavior. We recommend behavior analysts teach parents to use kernels and combinations of kernels (practices) that are based on the following 11 established behavior-change strategies:

1. Access to immediate, certain, high-magnitude social reinforcement

2. Feedback and discriminative stimuli that serve as reminders of the desired rules and routines

3. Graduated demands that build momentum to following the rules and routines

4. Alternatives to attention for unwanted behavior

5. Clear, firm responses to dangerous conduct and reinforcement for changing to nonhazardous behavior

6. Observation of thoughts as rules that can be differentially applied or dismissed as the context warrants

7. Observation of emotions as useful guides that do not demand immediate action

8. Flexible attention to the present moment

9. Alternate, nonexclusive ways of viewing self and others

10. Identification of values (statements that organize behavior toward powerful, durable reinforcers)

11. Committed action that is consistent with stated values

\section{Categories of Evidence-Based Kernels}

The behavior-change strategies listed previously form the foundation upon which evidence-based kernels are situated. Embry (2008) and Embry (1984)described four distinct categories of evidence-based kernels that are easily taught and used in clinical contexts. Kernels may alter the potency of behavioral consequences. For example, making a prize bowl 
transparent and just out of a learner's reach increases the value of the reinforcers found within the bowl. Alternatively, kernels may affect behavior primarily via antecedent control. A red card placed on the kitchen door when it is off limits, and a green card placed on the door when it is okay to enter, is an evidence-based kernel that decreases dangerous behavior and increases engagement in other activities. Kernels may also affect behavior by evoking relational framing. When a parent reinforces sharing by saying, "What you just did was great, Pietra. In this family we share because sharing is our superpower," the parent has promoted deictic framing, or perspective taking with respect to the family unit. The parent has also facilitated the child's use of hierarchical framingcategorizing "sharing" as a prosocial behavior that is likely to be reinforced by other family members. And the parent has formed an augmental, "sharing is our superpower," a phrase that when repeated often alters the value of giving things away and helps evoke this behavior. Finally, kernels may affect behavior through physiology. Getting the family together for a run or a yoga session increases everyone's heart rates and reduces the adverse effects of being stationary within the house for long periods of time. Each of these kernels has an evidence base that is beyond the scope of this article to include. For a more thorough explanation, see Embry and Biglan (2008).

\section{Kernel-Informed Practices}

Fundamental behavior-change strategies and evidence-based kernels can be incorporated into daily kernel-informed practices that are easily taught with simple, scalable rules. We wish to emphasize that any of the practices that we recommend in the following sections can be focused as we suggest or refocused toward a different outcome that is more suitable to the context of a particular parent, child, or family. The practice categories we describe in this article include exercises that (a) promote the use of schedules and routines, (b) promote family values and norms, (c) increase positive reinforcement, and (d) serve as antecedents for prosocial behavior.

The practices we recommend, listed and categorized here, include games and strategies that invoke no less than two of the aforementioned kernels and are easily adapted to focus on others. In fact, the practices we list herein are important because of their robust flexibility; they can be reused frequently, changed in an infinite number of ways, and tailored to the needs of a range of users. Behavior analysts are encouraged to modify the practices as needed so that the right kernels are promoted at the right time with the right family and taught to others by the right family member (Paul, 1969).

We also encourage behavior analysts to go well beyond teaching these kernels to clients. We urge behavior analysts to spread these protective, preventive strategies widely through communities, organizations, and media. The whole point of handwashing as a public-health strategy is to reduce not only sepsis as described by Semmelweis (Pittet \& Allegranzi, 2018) but also the epidemic. For example, Embry and colleagues used simple self-modeling stories to reduce pedestrian injuries to young children (Embry, 1984), which could be easily adapted to children helping keep a home "virus-free" by washing their hands in a self-modeling story using mobile phone photos and a simple script (Embry, 1980).

\section{Promote the Use of Schedules and Routines}

1. Help parents establish clear expectations. Research demonstrates that providing verbal and visual reminders of rules can increase appropriate behavior at the level of the individual (e.g., Faul, Stepensky, \& Simonsen, 2012; Moore et al., 2019) and at the level of the group (e.g., Chinnappan, Rapp, \& Burkhart, 2019; Hamrick, Richling, Brogan, Rapp, \& Davis, in press) in classroom settings. Together, these studies provide evidence that rules can help decrease problem behavior across various populations. This strategy of simply providing verbal and/ or written reminders of rules is particularly useful as it involves low-effort behavior on the part of the implementer. To whatever extent desired, the entire family can be involved in establishing acceptable rules to be followed within the household. An additional strategy would be to let children know that when they implement contingencies for each other, or remind each other of the rules, they are being heroic. Everyone needs a reminder once in a while. For example, most of us touch our faces often. We have been told that this is a dangerous practice, but without prompts regarding the expectation, we are likely to rub our noses and eyes, thus increasing the risk of COVID-19 infection.

2. Use activity schedules. Activity schedules can be utilized to help promote independent behavior (e.g., McClanahan \& Krantz, 1999), to increase on-task behavior (e.g., Bryan \& Gast, 2000), and to create smooth transitions between activities (e.g., Dooley, Wilczenski, \& Torem, 2001). Parents can be encouraged to construct interactive and visually stimulating textual and/or pictorial schedules to create structure in the home environment. This can help give structure around transitions during both typical home activities (e.g., getting ready in the morning) and not previously typical home activities (e.g., homeschooling, teleconferencing with teachers). In addition, to the extent possible, children can be included in creating the schedule and be given a choice in the order of activities (Kern et al., 1998; Watanabe \& Sturmey, 2003). Involving the children in the constructing of the schedule and providing them with choices may help promote a sense of independence 
and control over their own environment, especially at a time when there is little control over many other circumstances.

3. Teach parents to use timers. Timers can be used in a variety of ways. One evidence-based strategy is called "Beat the Timer." In this exercise, learners are instructed that if they complete tasks before the timer runs out, they win a prize. Beat the Timer can be programmed with independent, interdependent, or dependent contingencies (Adams \& Drabman, 1995; Ball \& Irwin, 1976). Be sure to set this up as a fun challenge and avoid a time-based requirement that may be stressful and result in negative punishment for "trying." Timers can also be used to aid in transitions from one activity to the next and function as a visual or auditory cue for upcoming shifts among activities. The timer is a simple technology that can evoke appropriate behavior, increase the independence of the learner, and decrease response effort on the part of the parent.

4. Give "tootles." Family members can be given a stack of cards with spaces for writing another person's name and what that person has done. They are instructed to look for others engaging in prosocial behavior and to write a "tootle," or a praise note that can be posted on a wall, read aloud, or placed in a photo album of praiseworthy moments (Cabello \& Terrell, 1994; Embry et al., 1996). During family conflicts and other stressful situations, offering a tootle for something a sibling does is a remarkably heroic act that runs counter to most children's social conditioning and reinforcement histories. Yet doing so can defuse explosive situations and improve the likelihood of reciprocal reinforcement from others. Teaching children that giving tootles is a superpower and challenging them to try it and see what happens can improve their probability of contacting much-needed reciprocal reinforcement from their brothers and sisters.

\section{Promoting Family Values and Norms}

1. Support empathic and perspective-taking behavior. Behavior analysts have begun to adopt strategies for teaching empathic responding and perspective taking with children diagnosed with autism (e.g., Schrandt, Townsend, \& Poulson, 2009). In addition, these behaviors may be useful among siblings, children to parents, parents to children, and among partners and other family members to create therapeutic support networks and help build tolerance for or alleviate stress across the family unit (Arciniega, Szabo, \& Tarbox, 2020; Szabo, 2019; Szabo et al., 2020). For example, Arciniega et al. (2020) taught experimenters to use empathic statements when listening to the concerns of siblings who had been aggressive with children with autism, and then taught the participants to use similar empathic statements when engaging in activities with their siblings with autism. To further supplement this skill, members of the family may be taught to first engage in value-clarification exercises. For example, after drawing a coat of arms with four to six sections, family members can illustrate those aspects of their connection with each other that are of the highest value to them (Asen \& Scholz, 2009). Sections of the coat of arms could include images of superpowers that family members use to protect one another's health and well-being.

2. Use a 5-min pause: acting without reacting. Stay-athome orders are likely to increase the frequency of verbal conflicts between parents. Children observe the actions of their parents, and if parent actions are reinforced, children are likely to imitate what they see. Parents may be negatively reinforced when using coercion in their interactions with each other, and thereby teach their children to do the same. Behavior analysts should discuss the way that these practices are transmitted from parents to their children through the parents' unintentional modeling of them. Parents can therefore be taught to pause before responding to conflict or stressful disagreements with others. The practice of pausing when agitated can be discussed with children as a heroic family value and established as a norm that is immediately reinforced by adults (Szabo et al., 2020).

3. Use a Jumble Jar. Sitting still and remaining at family meals may be challenging for many children because it is not clear what they will talk about and because topics preferred by parents (e.g., the latest news on COVID19) may not be preferred by children. A Jumble Jar provides structure to family meals and a simple way for members to connect with themselves and each other. A jar is filled with sentence starters, or "jumbles," that family members take turns pulling from the jar and discussing during meals (e.g., Price \& Nelson, 2019). Family members should be instructed to use active listening skills (e.g., "I hear you saying that you dream of going snorkeling because you want to learn about sea creatures.") and to ask respondents to expand on shorter answers that they offer. Here are a few examples:

- "What are two things you thought about doing that you can wait on and do some other time?"

- "When I'm really down, my feelings are as big as a and as heavy as a

- "Something I used to be scared of but now I like is ,"

- "When I'm all alone, I pretend I'm a ___ because then I can do . ."

- "I dream of doing ___ with my friends." 
- "So that I can someday do something really great, right now, I practice ."

- "One of the things I like most about this family is ,

- "One thing I would like to hear more of in our family is "

- "One thing I would like to do more with my family when we are at home is "

- "One thing I am proud of about myself is .

4. Use daily visioning. Families can be instructed to begin their day by reciting a written statement of their family vision and constructing a list of activities for the day that are consistent with their vision. This can be combined with the creation of activity schedules, as described earlier. The daily vision can state the family's position on how to face challenges (e.g., "Our family steps up to the plate when things get tough, and we do our part to help others."). The combination of the day's activities constitutes a vaccination schedule aimed at reducing toxic and unsafe behavior (Embry \& Biglan, 2008).

5. Use value-clarification exercises. Identifying patterns of behavior that orient toward large, remote reinforcers often makes engaging in these behaviors themselves reinforcing. One simple activity that can be repeated and modified each time it is used is the Life Timeline. Tape can be stretched out across the floor or carpet, and photos or drawings of important life events are then laid chronologically on top of the timeline tape. Family members can then take turns talking about how these events impacted them, what they learned, and how they use what they learned then in their current circumstances (Flentroy, Young, Blue, \& Gilbert, 2015).

\section{Increasing Positive Reinforcement}

1. Target and reinforce patience and resilience. In general, behavior analysts teach replacement behaviors that are functionally equivalent to unwanted behaviors. However, some situations in which children engage in escapemaintained behavior cannot or should not be escaped from. When ordered to stay at home, children must do so, even if the home environment is cramped and avoiding others is impossible. To address these situations, behavior analysts should teach tolerance to nonpreferred activities and situations using graduated exposure and reinforcement (e.g., Cook, Rapp, \& Schulze, 2015; O'Rourke, Richling, Brogan, McDougale, \& Rapp, 2019). Increasing rates of, lengthening durations of, or shortening delays to reinforcement improve the efficiency and effectiveness of graduated exposure to nonpreferred activities and situations. Additionally, verbal augmentals such as "Superheroes model being patient with their sisters and brothers. I love seeing you show your brother how to be so patient" serve to increase the reinforcing effectiveness of others seeing a child behaving resiliently.

2. Make use of group contingencies among siblings. The PAX Good Behavior Game (PAX GBG; Turkkan, 1988) is a set of practices that improve norms in the home environment. The school-based version of the PAX GBG is being used in more than 50,000 classrooms across three nations and is impacting more than a million children and their families (PAXIS Institute, 2018). Empirical studies have shown behavioral and protective benefits in terms of problem-behavior reduction (Embry, 2002), improved physical health (Krug et al., 1997), and improved emotional health (Jiang, Santos, Josephson, Mayer, \& Boyd, 2018; Wilson, Hayes, Biglan, \& Embry, 2014). In the home environment, behavior analysts can ask families to map the things that they would like to see, hear, feel, and do more of and also less of in their homes. The map of these four kinds of events can be colorful and pictorial if doing so will serve as a discrimination and self-regulation aid. The PAX GBG follows and is used anytime the family engages in challenging activities, such as personal care routines or academic tasks. The family can be divided into teams, and for the duration of the game, one parent announces how each team is doing. Parents can also be members of the teams in smaller families. For $1 \mathrm{~min}$ at first, and subsequently longer intervals afterward, teams aim to remain focused and engaged in specified, desirable ("good") behaviors. After each interval, teams that met the criterion celebrate with 10-s giggle fests, tickles, or other preferred activities. As with other practices in this section, the PAX GBG can be mixed with other kernels to promote desired family norms (Jack et al., 2020). The classroom version can be easily adapted to fit family contexts (Embry \& Biglan, 2008), and the general strategy has had systematic and direct replications in the United States, Canada, Europe, and Australia presently (e.g., Kellam \& Anthony, 1998; Kellam et al., 2014).

3. Incorporate games to provide opportunities for frequent reinforcement.

Math Mountain. Homeschooling and keeping up with academics can be challenging for parents who have never tutored their children before. Turning academics into games adds play and adventure to tasks that might otherwise be difficult to engage children in. In Math Mountain, a rock cliff is climbed in several "pitches" or rope lengths. Each player leads a pitch by solving a math problem that is adjusted to his or her individual math skill level. When each player has solved a problem, the team arrives at the top of the mountain and must now rappel down the 
other side by each person solving another problem. Teammates earn bonuses for helping each other without solving the problems for each other. Parents can include metaphors to transform the functions of the aversive properties of math (e.g., teammates may be encouraged to "climb past Frustration Yeti") or may use metaphors to reconnect with family values (e.g., "We are all tied together on the same rope in this climb. In this family, no one gets left behind. And if you fall off the cliff by getting a problem wrong, I promise I'll use our climbing rope to catch you, and you will be safe to climb back up.").

Computer Cleanup. Computers need to be cleaned periodically to ensure optimal performance. So do family rooms, dining rooms, and kitchens. Computer Cleanup makes use of the Premack principle (Premack, 1959) in a concurrent-chains preparation to promote delayed gratification:

- Clean for 5 min to earn 10 min of computer time.

- Clean for $10 \mathrm{~min}$ to earn $25 \mathrm{~min}$ of computer time.

- Clean for $15 \mathrm{~min}$ to earn $40 \mathrm{~min}$ of computer time.

Participants can select which of the previous three schedules they will try. In each of the schedules, the following rules apply:

1. "Put things away where they belong."

2. "Use cleaning products safely."

3. "Talk while you work as long as you keep working."

4. "If you stop working for a minute, it's cool; just add a minute to the work time."

5. "If you finish early and help someone else, you earn bonus minutes of computer time."

\section{Antecedent Strategies}

1. Noncontingent attention and displays of interest. Antecedent strategies are simple and useful to decrease the chance of problem behavior occurring at the level of the individual and also for groups of individuals (e.g., McDougale et al., 2019). Parents can be taught to utilize timers to deliver noncontingent attention and interest in the form of asking questions or making comments about an activity the child is engaged in or providing statements of empathic support on manageable, periodic, time-based schedules.

2. Designated activity spaces/rooms. It may be helpful for some learners who have difficulty transitioning from one activity to the next to be provided with visual cues, such as pictures, indicating the next activity on an activity schedule so that they can match that visual cue to one placed where that activity is to take place (Schmit,
Alper, Raschke, \& Ryndak, 2000). Designating areas or rooms within the home for specific activities (e.g., meditation, work, art) may help to promote stimulus control and increase compliance and on-task behavior. The family and children may come up with fun names for the designated spaces and correspond them to the activity schedule. Rotating among different spaces within the home may also help to alleviate environmental satiation through dishabituation. Similarly, to help with potential sleep problems, children should not be allowed to do schoolwork or watch television in bed. Instead, a nighttime routine can be established that involves activities such as bathing, brushing teeth, being read to, and so on to help evoke compliance and elicit sleep (Marquenie, Rodger, Mangohig, \& Cronin, 2011).

3. Present-moment exercises. There are simply too many stimuli competing for our attention during the COVID-19 crisis. Both overt stimuli (e.g., social media, television news) and covert verbal stimuli (e.g., thoughts and worries about what the future may bring) can distract much-needed attention away from effective parent-child interaction strategies. Paying attention to present-moment stimuli is a behavioral skill repertoire that can be strengthened and generalized through practice and reinforcement across multiple tasks, settings, times of day, and sensory modalities (Little, Tarbox, \& Alzaabi, 2020).

Pet your pet. Family pets are stimuli that can bring the behavior of paying attention under the control of the present context. Human behavior that is otherwise easily distracted by worries about the past and the future can be refocused on the present moment by asking family members to pet and find the softest part of their animal. This is often a preferred activity for pets and children alike (Feuerbacher \& Wynne, 2015). Try taking a few deep, slow breaths while petting the pet and really focus on the tactile experiences of the warmth and texture of the fur. Try connecting that experience to other more difficult aspects of your life (e.g., "If I can be this in the moment right now, maybe I can really be present while struggling with homeschooling my child.").

Five-min daily meditation. Useful for the whole family, meditation can be done lying down, walking, jogging in place, and even while doing household chores. Incorporate "doing one thing and one thing only" into each family member's activity schedule to improve focus and reduce defective stimulus control (Lunsky, Fung, Lake, Steel, \& Bryce, 2018). Daily meditation has been shown to improve challenging behaviors in individuals with developmental disabilities, both through direct training and via parent training (Singh \& Hwang, 2020). As with other new 
behaviors, it is important to use graduated exposure. A 1-min meditation may be the best place to start. Also, you can increase the value of this activity by teaching parents to let everyone know that even superheroes need to recharge their batteries, and this is how they do it. Parents can model doing one thing, and one thing only, by putting away their phones for fixed and specified periods of time, for example, while helping their child with a particular task.

5-4-3-2-1. It is easy to become overly focused on the past or the future; 5-4-3-2-1 encourages learners to bring their attention back to the present moment. Participants are asked to stand in place and describe five things they see, four things they hear, three things they can touch, two things they smell, and one thing they taste. Participants can be instructed to help each other with physical prompts or vocal probes. Parents can engage in this practice tooovertly with their children if it is fun, or covertly whenever they notice they are paying more attention to their private events than to what is happening here and now with their family.

\section{Discussion}

\section{Limitations}

Addressing each client and family in terms of the unique history and function of individual behaviors is a hallmark of the discipline of applied behavior analysis. Therefore, the strategies listed here cannot and should not be considered a panacea for all families and all of the unique challenges they face during this trying time. Although we believe the list of evidence-based strategies described here will be a useful addition to practitioners' tool kits, it is each behavior analyst's ethical responsibility to select individual strategies based on the assessed fit for individual families, in terms of behavioral function, family and systems resources, and cultural backgrounds, among other variables.

\section{Conclusion}

The current situation may prove to be a teachable moment for the nation. There are about 34 million families with children in the United States and many millions beyond the United States. These families are going to be spending far more time together than they typically have. Heretofore, the primary way in which families have been helped was via in-home and classroom or clinic meetings with individuals and small groups. The current crisis has created an unprecedented demand for parent support, but it has also forced us to curtail in-person services and, instead, interact via phone and Internet media. With simple exercises based on known principles, strategies, and kernels, behavior analysts connecting with parents online may be able to promote positive parenting to an extent that has never happened before. We have focused on ways to promote prosocial conduct in the home by pointing out that these actions are reflections of superpowers possessed by children. But it is equally true that parents, navigating an unprecedented situation with no lead time, are the unsung heroes of this era. The most important superpower of all is that with all the stress of this moment, a parent continues to get up in the morning and be a parent.

\section{Compliance with Ethical Standards}

Conflict of Interest The authors declare that they have no conflict of interest.

\section{References}

Adams, C. D., \& Drabman, R. S. (1995). Improving morning interactions: Beat-the-Buzzer with a boy having multiple handicaps. Child and Family Behavior Therapy, 17, 13-26. https://doi.org/10.1300/ J019v17n03 02 .

Amlen, D. (2020). Running out of games? Remember these old-school favorites. The New York Times. Retrieved from https://www. nytimes.com/2020/03/25/smarter-living/coronavirus-classic-games. html

Arciniega, A., Szabo, T. G., \& Tarbox, J. (2020). Improving sibling interactions using acceptance and commitment training. Manuscript in preparation, School of Behavior Analysis, Florida Institute of Technology.

Asen, E., \& Scholz, M. (2009). Multi-family therapy: Concepts and techniques. New York, NY: Routledge.

Ball, T. S., \& Irwin, A. E. (1976). A portable, automated device applied to training a hyperactive child. Journal of Behavior Therapy and Experimental Psychiatry, 7, 185-187. https://doi.org/10.1016/ 0005-7916(76)90082-3.

Bryan, L. C., \& Gast, D. L. (2000). Teaching on-task and on-schedule behaviors to high-functioning children with autism via picture activity schedules. Journal of Autism and Developmental Disorders, 30, 553-567. https://doi.org/10.1023/a:1005687310346.

Cabello, B., \& Terrell, R. (1994). Making students feel like family: How teachers create warm and caring classroom climates. Journal of Classroom Interaction, 29, 17.

Chinnappan, B., Rapp, J. T., \& Burkhart, B. R. (2019). Effects of rules and feedback on classroom behavior of adolescents in a residential treatment setting. Behavior Modification. Advance online publication. https://doi.org/10.1177/0145445519834637

Cook, J. L., Rapp, J. T., \& Schulze, K. A. (2015). Differential negative reinforcement of other behavior to increase wearing of a medical bracelet. Journal of Applied Behavior Analysis, 48(4), 901-906. https://doi.org/10.1002/jaba.228.

Corti, C., Pergolizzi, F., Vanzin, L., Cargasacchi, G., Villa, L., Pozzi, M., \& Molteni, M. (2018). Acceptance and commitment therapyoriented parent-training for parents of children with autism. Journal of Child and Family Studies, 27, 2887-2900. https://doi. org/10.1007/s10826-018-1123-3.

Dooley, P., Wilczenski, F. L., \& Torem, C. (2001). Using an activity schedule to smooth school transitions. Journal of Positive 
Behavior Interventions, 3, 57-61. https://doi.org/10.1177/ 109830070100300108

Embry, D. D. (1980). Designing instructional materials for young children. In J. Gallagher (Ed.), New directions in special education (p. 440). San Francisco, CA: Jossey-Bass.

Embry, D. D. (1984). The safe-playing program: A case study of putting research into practice. In S. Paine \& B. Bellamy (Eds.), Human services that work: From innovation to standard practice (p. 624). Baltimore, MD: Brookes Co.

Embry, D. D. (1991). The impact of Desert Storm on military families. Testimony before the U.S. Senate Veterans' Affairs Committee; Washington, DC. Retrieved from https://www.c-span.org/person/? dennisembry

Embry, D. D. (2002). The Good Behavior Game: A best practice candidate as a universal behavioral vaccine. Clinical Child and Family Psychology Review, 5(4), 273-297. https://doi.org/10.1023/a: 1020977107086.

Embry, D. D. (2004). Community-based prevention using simple, lowcost, evidence-based kernels and behavior vaccines. Journal of Community Psychology, 32, 575-591. https://doi.org/10.1002/ jcop. 20020 .

Embry, D. D. (2006). Psychological weapons of mass disruption through vicarious classical conditioning. In B. Bongar, L. Brown, B. Le, J. Breckenridge, \& P. Zimbardo (Eds.), Psychology of terrorism (pp. 164-174). Cambridge, UK: Oxford University Press.

Embry, D. D., \& Biglan, A. (2008). Evidence-based kernels: Fundamental units of behavioral influence. Clinical Child and Family Psychological Review, 11, 75-113. https://doi.org/10.1007/ s10567-008-0036-x.

Embry, D. D., Flannery, D. J., Vazsonyi, A. T., Powell, K. E., \& Atha, H. (1996). PeaceBuilders: A theoretically-driven, school-based model for early violence prevention. American Journal of Preventive Medicine, 12, 91-100. https://doi.org/10.1016/S0749-3797(18) 30241-1.

Faul, A., Stepensky, K., \& Simonsen, B. (2012). The effects of prompting appropriate behavior on the off-task behavior of two middle school students. Journal of Positive Behavior Interventions, 14, 47-55. https://doi.org/10.1177/1098300711410702.

Feuerbacher, E. N., \& Wynne, C. D. (2015). Shut up and pet me! Domestic dogs (Canis lupus familiaris) prefer petting to vocal praise in concurrent and single-alternative choice procedures. Behavioural Processes, 110, 47-59. https://doi.org/10.1016/j.beproc.2014.08. 019.

Flentroy, S. L., Young, M., Blue, N., \& Gilbert, D. J. (2015). Innovative assessment of childhood trauma and its link to HIV and substance abuse in post-incarcerated women. Journal of Creativity in Mental Health, 10, 351-363. https://doi.org/10.1080/15401383.2014. 985861

Hamrick, S., Richling, S. M., Brogan, K. M., Rapp, J. T., \& Davis, W. T. (in press). Effects of obtrusive observation and rules on classroom behavior in a juvenile residential treatment setting. Behavior Modification.

Jack, E. M., Chartier, M. J., Ly, G., Fortier, J., Murdock, N., Cochrane, B., et al. (2020). School personnel and community members' perspectives in implementing PAX Good Behaviour Game in First Nations grade 1 classrooms. International Journal of Circumpolar Health, 79, 1. https://doi.org/10.1080/22423982.2020.1735052.

Jiang, D., Santos, R., Josephson, W., Mayer, T., \& Boyd, L. (2018). A comparison of variable- and person-oriented approaches in evaluating a universal preventive intervention. Prevention Science, 19, 110. https://doi.org/10.1007/s11121-018-0881-x.

Kellam, S. G., \& Anthony, J. C. (1998). Targeting early antecedents to prevent tobacco smoking: Findings from an epidemiologically based randomized field trial. American Journal of Public Health, 88, 1490-1495. https://doi.org/10.2105/ajph.88.10.1490.
Kellam, S. G., Wang, W., Mackenzie, A. C. L., Hendricks Brown, C., Ompad, D. C., Or, F., et al. (2014). The impact of the Good Behavior Game, a universal classroom-based preventative intervention in first and second grades, on high-risk sexual behaviors and drug abuse and dependence disorders into young adulthood. Prevention Science, 15, S6-S18. https://doi.org/10.1007/s11121012-0296-z.

Kern, L., Vorndran, C. M., Hilt, A., Ringdahl, J. E., Adelman, B. E., \& Dunlap, G. (1998). Choice as an intervention to improve behavior: A review of the literature. Journal of Behavioral Education, 8, 151169. https://doi.org/10.1023/A:1022831507077.

Krug, E. G., Brener, N. D., Dahlberg, L. L., Ryan, G. W., \& Powell, K. E. (1997). The impact of an elementary school-based violence prevention program on visits to the school nurse. American Journal of Preventive Medicine, 13(6), 459-463. https://doi.org/10.1016/ S0749-3797(18)30142-9.

Little, A., Tarbox, J., \& Alzaabi, K. (2020). Using acceptance and commitment training to enhance the effectiveness of behavioral skills training. Journal of Contextual Behavioral Science, 16, 9-16.

Lunsky, Y., Fung, K., Lake, J., Steel, L., \& Bryce, K. (2018). Evaluation of acceptance and commitment therapy (ACT) for mothers of children and youth with autism spectrum disorder. Mindfulness, 9, 1110-1116. https://doi.org/10.1007/s12671-017-0846-3.

Marquenie, K., Rodger, S., Mangohig, K., \& Cronin, A. (2011). Dinnertime and bedtime routines and rituals in families with a young child with an autism spectrum disorder. Australian Occupational Therapy Journal, 58, 145-154. https://doi.org/10.1111/j.14401630.2010.00896.x.

McClanahan, L. E., \& Krantz, P. J. (1999). Activity schedules for children with autism: Teaching independent behavior. Bethesda, MD: Woodbine House.

McDougale, C. B., Coon, J. C., Richling, S. M., O’Rourke, S., Rapp, J. T., Thompson, K. R., \& Burkhart, B. R. (2019). Group procedures for decreasing problem behavior displayed by detained adolescents. Behavior Modification, 43(5), 615-638. https://doi.org/10.1177/ 0145445518781314

Moore, T. C., Alpers, A. J., Rhyne, R., Coleman, M. B., Gordon, J. R., Daniels, S., et al. (2019). Brief prompting to improve classroom behavior: A first-pass intervention option. Journal of Positive Behavior Interventions, 21, 30-41. https://doi.org/10.1177/ 1098300718774881

Murrell, A. R., Wilson, K. G., LaBorde, C. T., Drake, C. E., \& Rogers, L. J. (2008). Relational responding in parents. The Behavior Analyst Today, 9(3-4), 196-214. https://doi.org/10.1037/h0100659.

O’Rourke, S., Richling, S., Brogan, K., McDougale, C., \& Rapp, J. T. (2019). Tolerance training with adolescents in a residential juvenile facility. Behavior Modification. Advance online publication. https:// doi.org/10.1177/0145445519890261

Osmanski, S. (2020). Avoid cabin fever with these 125 ideas to keep kids entertained during the coronavirus crisis. Parade. Retrieved from https://parade.com/1009774/stephanieosmanski/things-to-do-withkids-during-coronavirus-quarantine/

Paul, G. L. (1969). Behavior modification research: Design and tactics. In D. M. Franks (Ed.), Behavior therapy: Appraisal and status (pp. 29 62). New York, NY: McGraw-Hill.

PAXIS Institute. (2018). About PAX science. Retrieved on March 31, 2020, from https://www.goodbehaviorgame.org/pax-science

Pittet, D., \& Allegranzi, B. (2018). Preventing sepsis in healthcare-200 years after the birth of Ignaz Semmelweis. Eurosurveillance, 23(18). https://doi.org/10.2807/1560-7917.ES.2018.23.18.18-00222

Premack, D. (1959). Toward empirical behavioral laws: I. Positive reinforcement. Psychological Review, 66, 219-233. https://doi.org/10. 1037/h0040891.

Price, K. M., \& Nelson, K. L. (2019). Planning effective instruction: Diversity responsive methods and management. Belmont, CA: Cengage. 
Schmit, J., Alper, S., Raschke, D., \& Ryndak, D. (2000). Effects of using a photographic cueing package during routine school transitions with a child who has autism. Mental Retardation, 38, 131-137. https://doi.org/10.1352/0047-6765(2000)038<0131:EOUAPC $>2.0$. $\mathrm{CO} ; 2$.

Schrandt, J. A., Townsend, D., \& Poulson, C. (2009). Teaching empathy skills to children with autism. Journal of Applied Behavior Analysis, 42(3), 17-32. https://doi.org/10.1901/jaba.2009.42-17.

Singh, N. N., \& Hwang, Y. S. (2020). Mindfulness-based programs and practices for people with intellectual and developmental disability. Current Opinion in Psychiatry, 33(2), 86-91. https://doi.org/10. 1097/YCO.0000000000000570.

Szabo, T. G. (2019). Acceptance and commitment training for reducing inflexible behaviors in children with autism. Journal of Contextual Behavioral Science, 12, 178-188. https://doi.org/10.1016/j.jcbs. 2019.03.001.

Szabo, T. G., Bockarie, H., White, R., Tarbox, J., Stewart, C., \& Ebert, B. (2020). Microaggression, gender-based intimate partner violence, and behavioral flexibility training in Sierra Leonean couples. Manuscript in preparation, School of Behavior Analysis, Florida Institute of Technology.

Turkkan, J. (1988). The Good Behavior Game manual. Baltimore, MD: John Hopkins School of Hygiene and Public Health, Department of Mental Hygiene.

U.S. Department of State. (2011). Sierra Leone 2011 human rights report. https://www.justice.gov/sites/default/files/eoir/legacy/2013/ 06/10/Sierra\%20Leone_5.pdf\#page $=25$

U.S. Department of State. (2012). Sierra Leone 2012 human rights report. https://www.justice.gov/sites/default/files/eoir/legacy/2013/ 06/10/Sierra_Leone.pdf\#page $=25$

U.S. Department of State. (2013). Sierra Leone 2013 human rights report. https://2009-2017.state.gov/documents/organization/ 220368.pdf
U.S. Department of State. (2014). Sierra Leone 2014 human rights report. https://www.justice.gov/sites/default/files/pages/ attachments/2015/08/03/dos-hrr_2014_sierra-leone_0.pdf\#children

U.S. Department of State. (2015). Sierra Leone $201 \overline{5}$ human rights report. https://www.justice.gov/sites/default/files/pages/ attachments/2017/06/06/dos-hrr_2015_sierra-leone.pdf\#page=21

U.S. Department of State. (2016). Sierra Leone 2016 human rights report. https://www.justice.gov/sites/default/files/pages/ attachments/2017/03/06/dos-hrr_2016_sierra_leone.pdf\#page=21

U.S. Department of State. (2017). Sierra Leone 2017 human rights report. https://www.justice.gov/eoir/page/file/1056151/download\# page $=16$

U.S. Department of State. (2018). Sierra Leone 2018 human rights report. https://www.justice.gov/file/1146611/download\#page=18

U.S. Department of State. (2019). Sierra Leone 2019 human rights report. https://www.justice.gov/eoir/page/file/1257541/download\# page $=18$

Watanabe, M., \& Sturmey, P. (2003). The effect of choice making opportunities during activity schedules on task engagement of adults with autism. Journal of Autism and Developmental Disorders, 33, 535-538. https://doi.org/10.1023/A:1025835729718.

Wilson, D. S., Hayes, S. C., Biglan, A., \& Embry, D. D. (2014). Evolving the future: Toward a science of intentional change. Brain and Behavioral Sciences, 37, 395-416. https://doi.org/10.1017/ S0140525X13001593.

Woidneck, M. R., Morrison, K. L., \& Twohig, M. P. (2014). Acceptance and commitment therapy for the treatment of posttraumatic stress among adolescents. Behavior Modification, 38(4), 451-476. https:// doi.org/10.1177/0145445513510527.

Publisher's Note Springer Nature remains neutral with regard to jurisdictional claims in published maps and institutional affiliations. 